\title{
HIGH SPEED ELECTROMECHANICAL ENERGY STORAGE
}

\author{
Artur Rowiński, Andrzej Irzycki, Krzysztof Snopkiewicz
}

\author{
Institute of Aviation \\ Krakowska Av. 110/114, 02-256 Warsaw \\ tel.: $+48228460011 w 316$, fax: +488465774 \\ e-mail:artur.rowinski@ilot.edu.pl \\ andrzej.irzycki@ilot.edu.pl
}

\begin{abstract}
Kinematical, electromechanical energy accumulator is a facility that converts supplied electrical energy to the kinetic one, stored in the rotating inertial system. Electric driving motors can operate both as a propulsion units, providing torque to the rotor shaft, and as generators in the course of braking. The prototype is designed to operate in a vacuum; the energy accumulator is located in a sealed pressurized vessel connected to the apparatus, which can generate vacuum pressure down to $1 \mathrm{~Pa}$. The accumulator is destined for storage energy of 7.2 MJ at a speed of up to 20,000 1 / min. The energy accumulator is equipped with inert weight in the form of metal disc, connected to a composite band. In the course of operation, the rotor assembly is suspended in noncontact manner in housing assembly while the main body is fastened to the inner ring of the pressure vessel. The rotor consists of a shaft on which are mounted: a metal disc together with a band made of carbon fibre, inset into inert weight using epoxy resin; four disc rotors of two electric motors; two disks which are magnetic armature for electromagnetic bearings operating along the shaft axis; bushings of both sleeve bearings; fixing sleeves, washers and lock nuts to fix particular elements on the shaft. During normal operation the rotor is positioned in the radial direction through two electromagnetic bearings, top and bottom, located at both ends of shaft and operating in the differential arrangement, and in the axial direction - by a system of two eight-pole electromagnetic bearings. In the idle state rotor is based on the spherical tip of the mobile support and on the raceway of slide bearing located in the top cover.

The prototype facility is designed to carry out performance tests, both under normal conditions of pressure and temperature and in vacuum environment, of: electromagnetic bearings, start-up/emergency devices, functional integration of all components and air tightness of tubing inside the tank. Measurement of radial and axial clearances between the rotor elements and housing for full speed range will be completed also.
\end{abstract}

Keywords: Kinematic energy storage, electric motors

\section{Introduction and specification of energy accumulator}

The prototype consists of the rotor unit (Fig. 1) suspended, during operation, in non-contact manner in the housing assembly. The main body is fastened to the inner ring of the pressure vessel. The drive unit of rotor comprises of two electric motors, between which a disc combined with inertial mass is placed.

The rotor consists of a shaft on which are mounted: metal disc with pasted inertia element band made of carbon fibre combined with epoxy resin (Fig. 2 and 3); four electric motors disks; two disks which are magnetic armature for electromagnetic bearings running along the shaft axis; bushings of both sleeve bearings and bushes fixing particular elements on the shaft. All elements are arranged using cantering surfaces that are positioned on the outer flanges of two shafts and side surfaces of inertia element bush discs. The main elements of the inertia system mounted on the rotor are a cylinder made of high strength alloy and a band made of composite material. The applied design ensures the maintenance of joint of both elements with an appropriate pressing force in the entire speed range. Flexibility of the inertia element barrel was increased by suitable shaping of their geometry and placement of the acting masses on the inner surface of the disc (Fig. 3). 


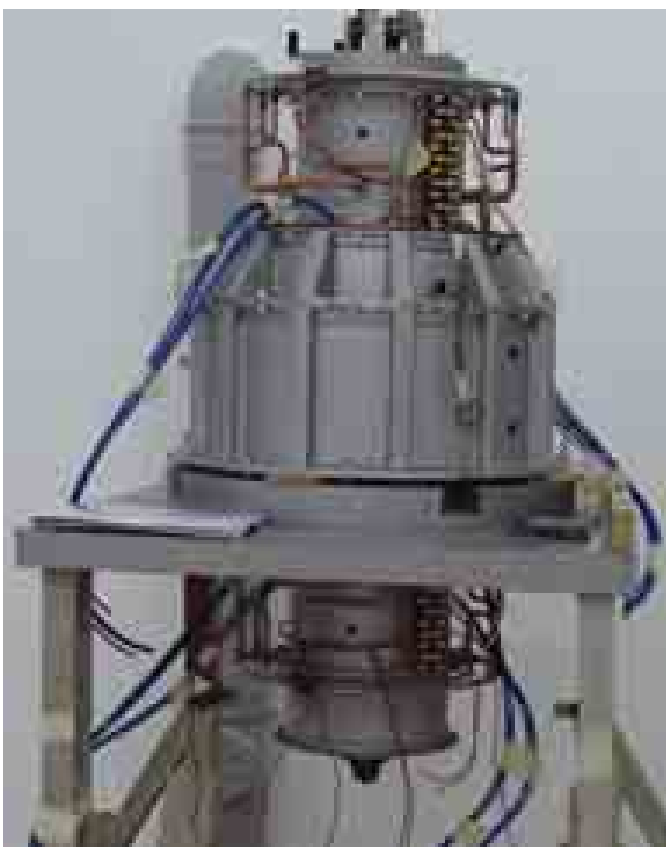

Fig. 1. Energy accumulator in the installation phase

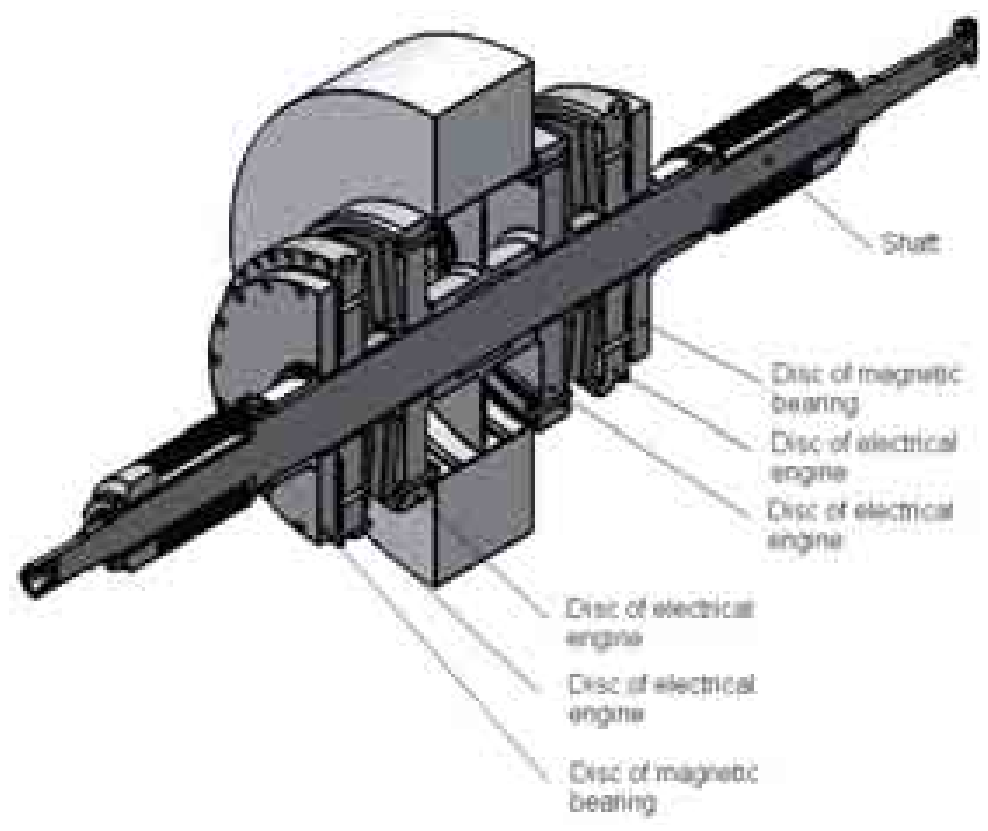

Fig. 2. Cross-section of energy accumulator rotor

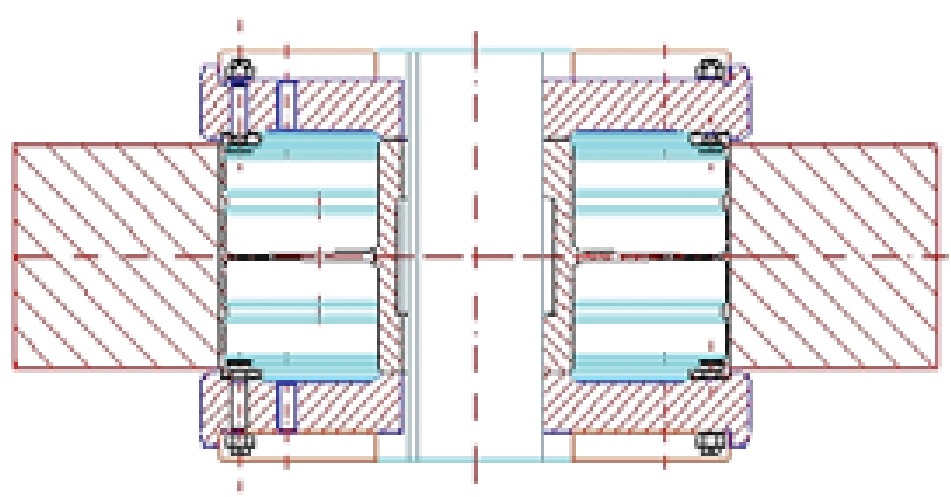

Fig. 3. Cross-section of inertia element and discs of electric motors 
The electric motors discs are mounted on the rotor (Fig. 1). During normal operation, the rotor is positioned in the radial direction by means of two electromagnetic bearings, top and bottom, located at both ends of shaft and in the axial direction - by a system of two electromagnetic bearings operating in the differential configuration. For idle state, the rotor is based on the spherical tip of the movable support and on the raceway of plane bearing located in the top cover. Start-up/emergency system provides a vertical support for rotor during starting phase (up to 4000 $\mathrm{rpm}$ ) and then guarantees disconnection of the support and rotor shaft keeping it in this orientation. In case of failure, the rotor will be supported on spherical tip of the shaft of lower movable support and slide bearing located on the upper shaft pivot.

The rotor shaft is borne in the housing using electromagnetic radial bearings. The raceway of inner bearing creates a magnetic core composed of two iron-silicon sheet packs (Fig. 1). The shaft location relative to the housing assembly, both in radial and axial directions, has been measured using eddy current method.

Movable support assembly of the rotor consists of shaft of the support, housing of the support, mechanism to establish tension force of resistance spring and shaft of movable support mounted on two roller bearings, which outer raceways are fixed using the bushings secured by fixing pin. The initial tension of the spring is established using selective washer and expansion ring. Selective spacer washer is used to determine the clearance between spherical end of the shaft and conical surface of the lower pivot of rotor.

The accumulator is equipped with a system to lock the rotor in the position providing proper clearance between itself and the elements of housings. Displacement of rotor in axial direction is blocked by two-position locking mechanism allowing hoisting of movable support to the upper position of the shaft. In this position, the upper plate of the keeper is in contact with magnetic core of upper electromagnet and precludes the rotation of the shaft.

The pressure tank consists of two separable covers bolted on a common flange. Each cover includes two tightly closed holes on spherical and cylindrical parts. Each of holes cap is equipped with pressurized canal lock, which serves a function of outlet for electrical, and measurement systems and cooling installation connected with external coolant tank. The lower cover is permanently connected to the tripod base. On the caps, carrying and mounting handles are installed as well.

\section{Computational models and numerical analysis}

The calculations were carried out for loads coming from inertial centrifugal forces at speed from 1000 or $20001 / \mathrm{min}$ up to $210001 / \mathrm{min}$, with module 2000 and loads originated from magnetic forces. In these calculations, contact phenomenon was taken into consideration, where the anisotropic model of material was applied for reproducing glue used to connect magnet with disk and the GAP - contact elements in one of considered models. Model of rotor accepted for calculation consists of a metal barrel (made of alloy with $\mathrm{E}=2.110^{\wedge} 6 \mathrm{MPa}$ and $v=0.3$ ) on which a composite band (made of carbon modular fabric 913C-HTA-5-35) is mounted.

The purpose of calculations using finite element method is to determine the allowable safe speed of rotor. The object of calculation is an assembly formed of disc of electric motor together with magnet, disk with band of inert weight, sleeve and raceways of electromagnetic bearing

Addition of concentrated mass on the barrel provided good contact of inert weight mass with barrel at large cylindrical surface, without changing the strength security level of construction.

\section{Summary}

The primary predicted application of the stationary electro-kinetic energy storage is:

- accumulation of energy produced by alternative energy sources (solar batteries, wind power plants), which are not incorporated into commercial state power system (autonomous systems),

- improving power quality in energetic power systems (voltage stabilization, mitigation of active power surges) or as a source of short-term backup supply for special manufacturing processes. 


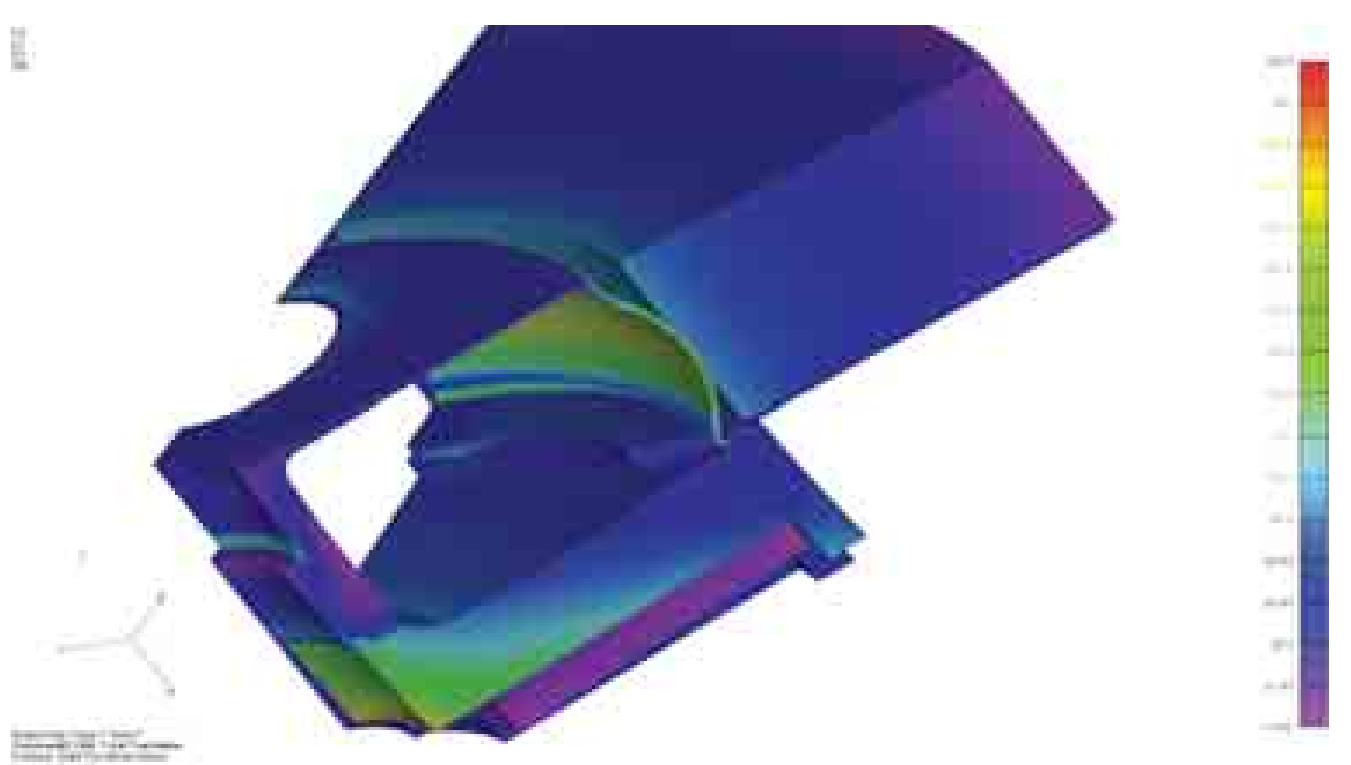

Fig. 4. Reduced stress in the metal-composite inertia element for $10000 \mathrm{rpm}$ (without concentrated mass)

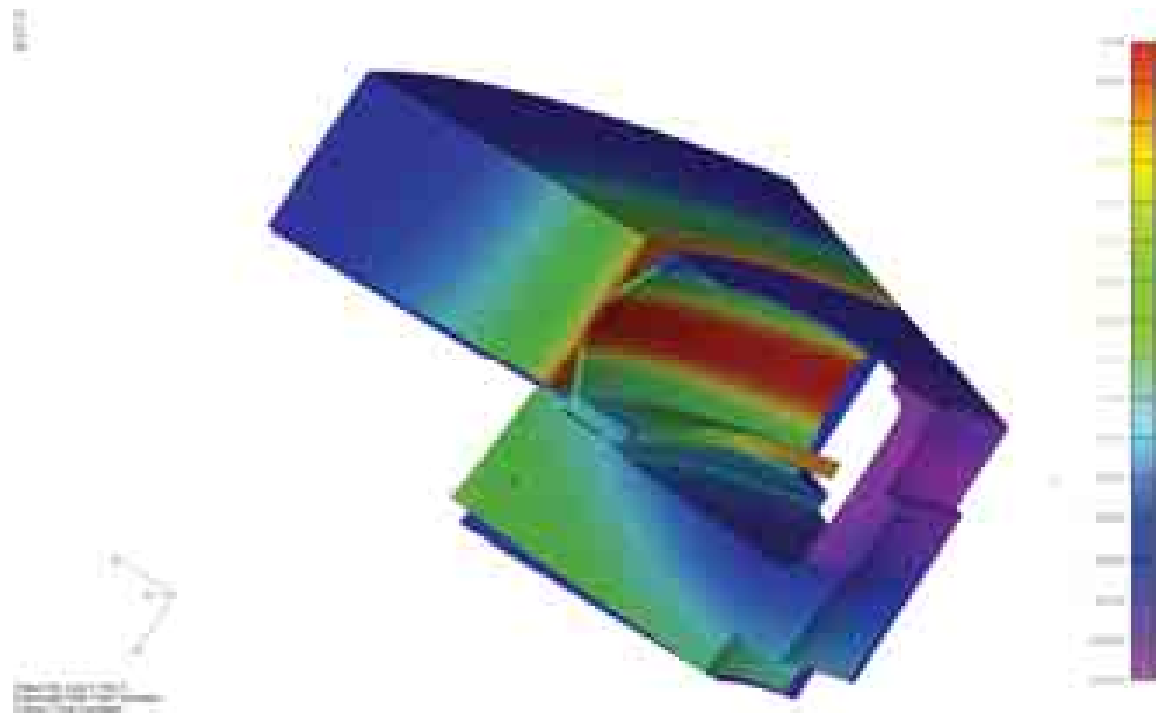

Fig. 5. Total displacement of nodes in computational model for $10000[\mathrm{r} / \mathrm{min}]$
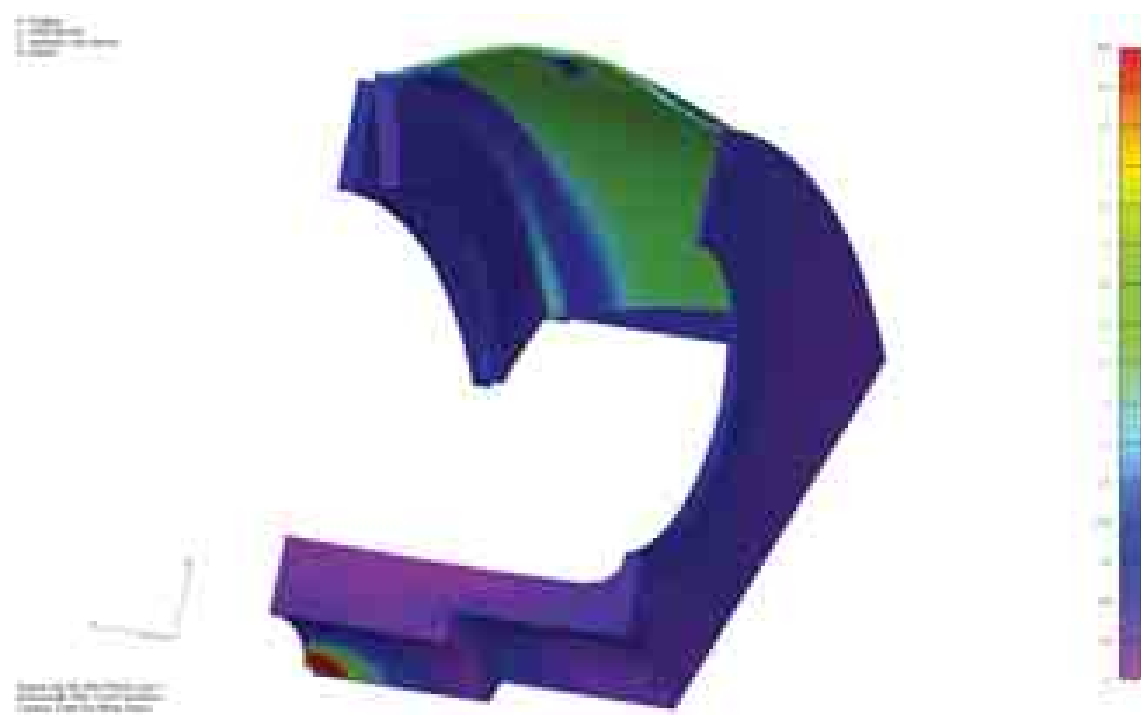

Fig. 6. Reduced stress levels in barrel computational model at $10000 \mathrm{rpm}$ with additional mass 


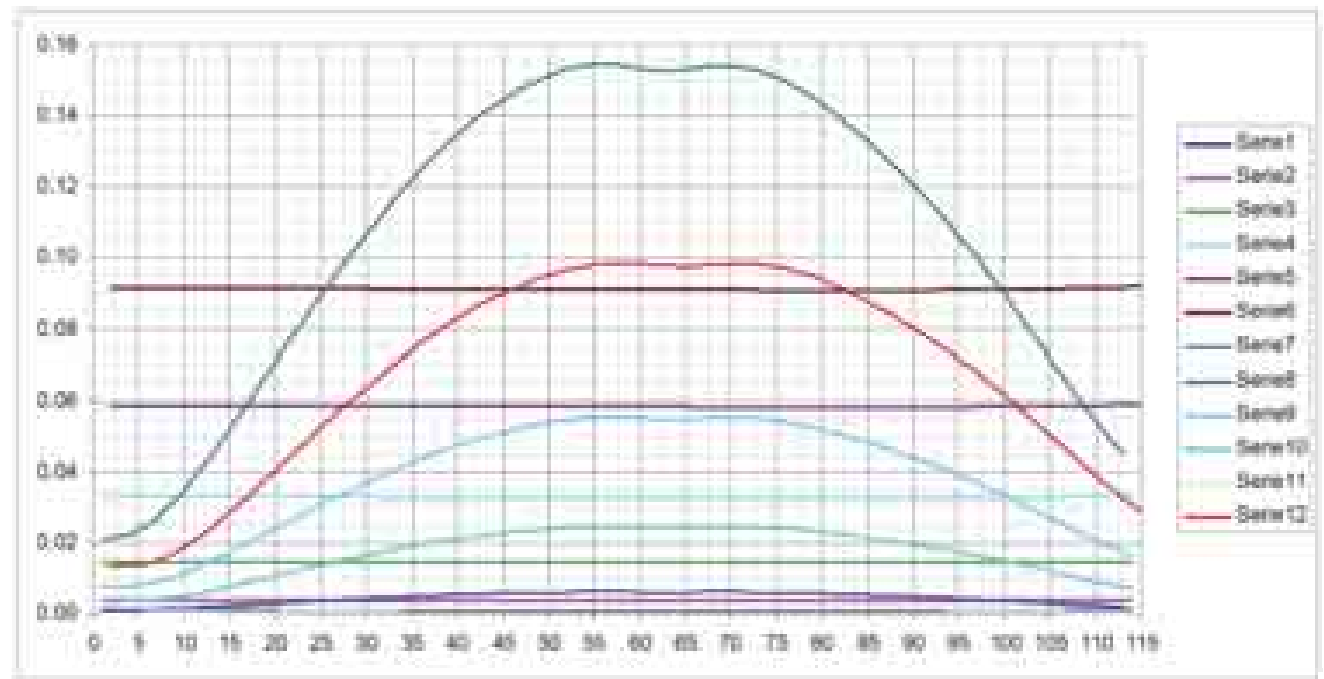

Fig. 7. Radial displacement of selected internal barrel circuits at 1000, 2000 up to $10000 \mathrm{rpm}$ with module 2000 모․
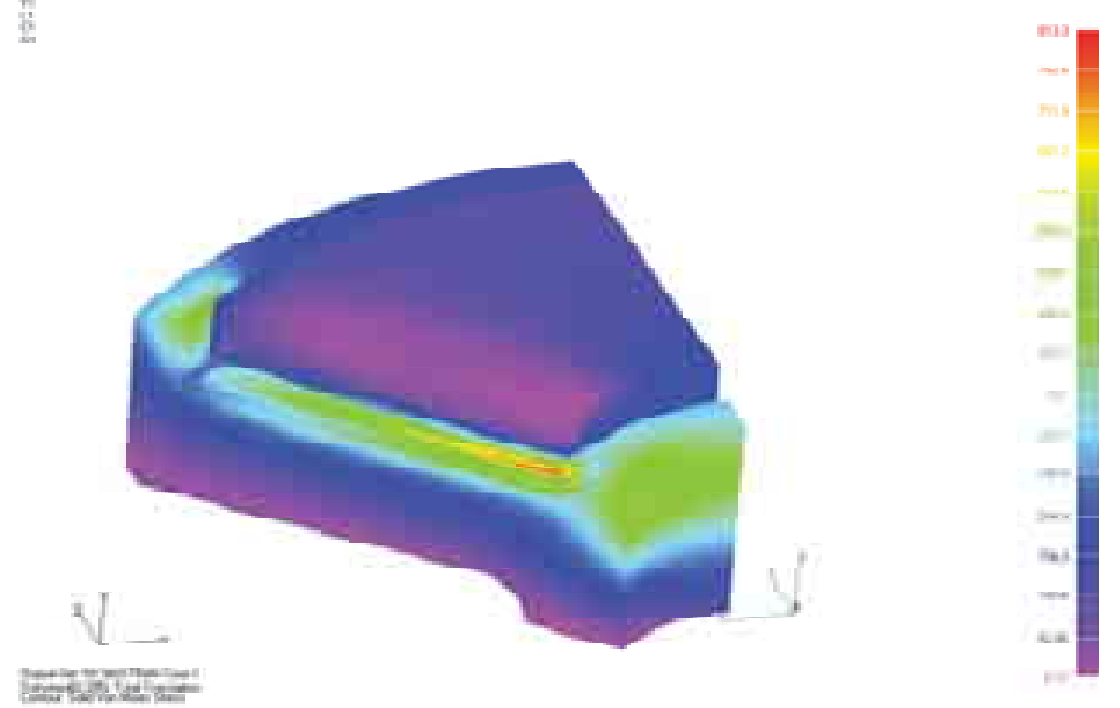

Fig. 8. Reduced stress in segment of electric motor disc for $21000 \mathrm{rpm}$

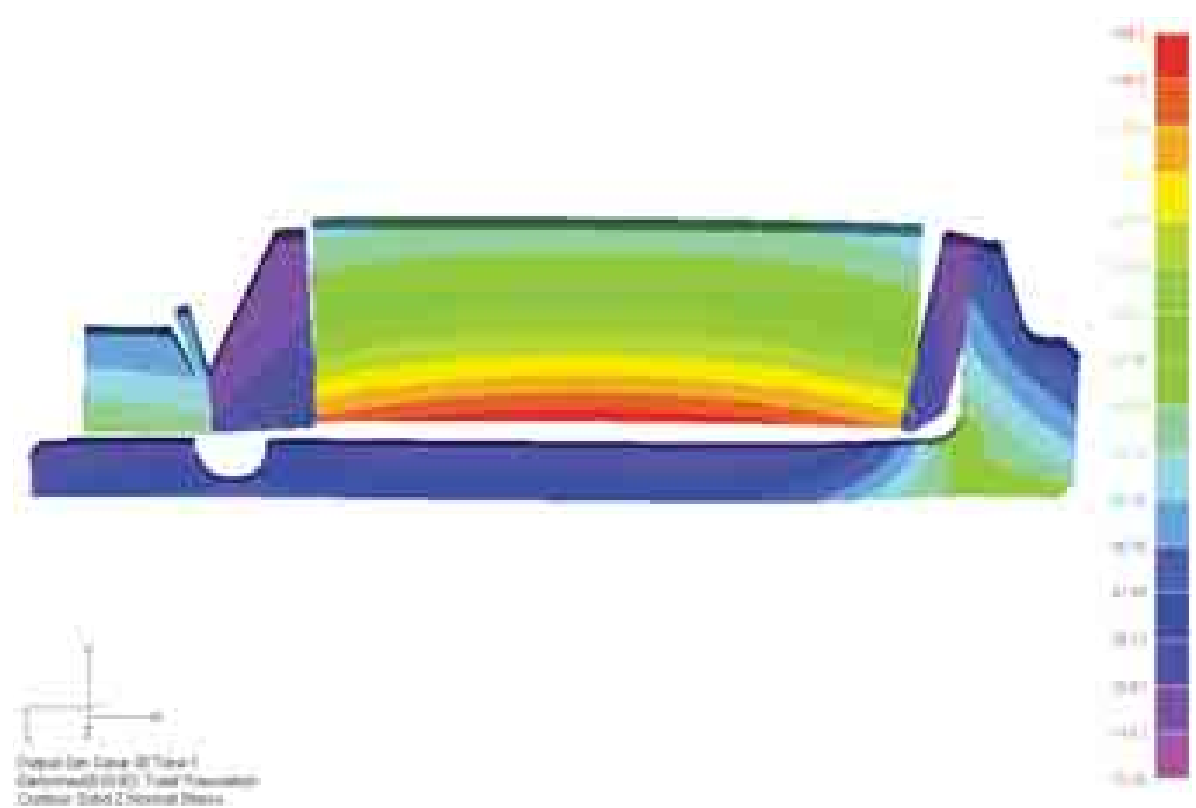

Fig. 9. Distribution of normal stress in the radial direction in the keeper of electromagnetic radial bearing 


\section{References}

[1] Brzoska, Z., Wytrzymałość materiałów, PWN, 1972.

[2] Przemieniecki, J. S., Theory of Matrix Structural Analysis Dover Publications INC, New York 1985.

[3] Cook, R. D., Finite Element Modeling For Stress Analysis, John Wiley and Sons, INC 1995.

[4] MSC / NASTRAN for Windows - Version 2.1, Update November 1996. 